OPEN ACCESS

Edited by:

João Pessoa,

University of Coimbra, Portugal

Reviewed by:

Nithya Balasundaram,

Christian Medical College \& Hospital,

India

loannis Ntanasis-Stathopoulos, National and Kapodistrian University of

Athens Medical School, Greece

*Correspondence:

Liang Zhou

liangzhou@suda.edu.cn orcid.org/0000-0003-0820-1520

Specialty section:

This article was submitted to Molecular and Cellular Oncology,

a section of the journal

Frontiers in Oncology

Received: 25 January 2022

Accepted: 15 February 2022

Published: 07 March 2022

Citation

Zhou L (2022) Caspase-8: Friend or

Foe in Bortezomib/Lenalidomide-

Based Therapy for Myeloma.

Front. Oncol. 12:861709.

doi: 10.3389/fonc.2022.861709

\section{Caspase-8: Friend or Foe in Bortezomib/Lenalidomide-Based Therapy for Myeloma}

\author{
Liang Zhou* \\ Department of Pharmacology, College of Pharmaceutical Sciences, Soochow University, Suzhou, China
}

Antiproliferation and proapoptosis are two major molecular mechanisms of action of drugs used for the treatment of multiple myeloma. Proteasome inhibitors, such as bortezomib (PS-341), and immunomodulatory drugs (IMiDs), such as lenalidomide, are the two drug types approved for the treatment of myeloma. Bortezomib and lenalidomide activate caspase- 8 and promote the apoptosis of myeloma cells. However, caspase- 8 inhibition potentiated the antiproliferative effect of lenalidomide and bortezomib in myeloma cells, suggesting that caspase- 8 could regulate proliferation and apoptosis in the opposite pathway. In this mini-review, I summarized recent advances in determining the molecular mechanisms of caspase-8 in bortezomib-lenalidomide-based therapy for myeloma and explored the possible functions of caspase- 8 in the proliferation and apoptosis of myeloma cells. Furthermore, future directions of caspase-8-based therapy for myeloma have been discussed.

Keywords: caspase-8, bortezomib, lenalidomide, myeloma cell, proliferation, apoptosis

\section{INTRODUCTION}

Caspase- 8 , as an initiator caspase, is essential for death receptor-dependent apoptosis $(1,2)$ and is activated in multiple pharmacological treatments for myeloma $(3,4)$. However, we have previously shown that caspase- 8 activation attenuates the anti-myeloma effect of bortezomib and lenalidomide $(5,6)$.

Thalidomide and its analogs lenalidomide and pomalidomide directly bind to the cereblon (CRBN) (7) and subsequently recruit neo-substrates IKZF1/3 to the CRL4 ${ }^{\mathrm{CRBN}}$ E3 ligase, thereby inducing ubiquitination and degradation of IKZF1/3 and exhibiting an anti-myeloma effect $(8,9)$. The indispensability of CRBN for the anti-myeloma effect $(10,11)$ indicates that upregulation of CRBN can potentiate the anti-myeloma effect of lenalidomide (12-14). Recently, we discovered that the proteasome inhibitors bortezomib and MG-132 could induce CRBN cleavage, which possibly attenuates the anti-myeloma effect of lenalidomide $(5,6)$. However, combination therapy with lenalidomide and bortezomib is the first-line pharmacotherapy for multiple myeloma $(15,16)$ and has led to the paradoxical therapeutic mechanisms that mediate the action of lenalidomide and bortezomib in myeloma (17).

In myeloma cells, bortezomib inhibits the functioning of the $26 \mathrm{~S}$ proteasome and affects multiple molecular pathways, including oxidative stress, NF- $\kappa \mathrm{B}$, and DNA damage and repair pathways, as well as classical intrinsic (mitochondria-dependent) and extrinsic (death receptor-dependent) cell 
death cascades, inducing the apoptosis of myeloma cells $(4,18-$ 20). Lenalidomide exhibits an anti-myeloma effect by increasing apoptosis and inhibiting the proliferation of myeloma cells (3, $21,22)$.

In this minireview, the caspase-8-involved extrinsic cell death cascade in bortezomib and lenalidomide therapy for myeloma was evaluated. First, I introduce the caspase- 8 signaling pathway in myeloma treatment. Second, I summarize the recent advances in bortezomib and lenalidomide treatment in multiple myeloma and survey the different biological roles of caspase- 8 in the treatment of myeloma. Finally, I discuss future perspectives on caspase-8-based therapy for myeloma.via cereblon IKZF1/ 3 cascade.

\section{CASPASE-8 AND "PROGRAMMED" CELL DEATH}

The Fas ligand (FasL, CD95 L) and tumor necrosis factor (TNF)$\alpha$ bind to the relative cell surface Fas receptor (CD95/Apo-1) and the tumor necrosis factor receptor, and then recruit the adaptor protein FADD and procaspase- 8 to form the death-inducing signaling complex (DISC), thereby activating caspase- 8 through cleavage, which is the extrinsic or death receptor apoptotic pathway (Figure 1A) (23). The activation of caspase- 8 for death receptor-mediated apoptosis occurs via two different molecular pathways. TNF- $\alpha$ cotreatment with cycloheximide activates caspase- 8 by eliminating c-FLIP, whereas TNF- $\alpha$ cotreatment with a Smac mimetic activates caspase- 8 by triggering the degradation of cIAP $1 / 2$ followed by the release of receptor-interacting serine-threonine kinase 1 (RIPK1/RIP1), thereby inducing apoptosis (24). Furthermore, lysosomal cathepsins might activate caspase- 8 in a death receptor- and mitochondria apoptotic pathway-independent manner (25). Besides its apoptotic functions, caspase- 8 affects other "programmed" cell death-necroptosis pathways by cleaving the death domain kinase RIP1 (RIPK1)/RIP3 (RIPK3) (Figure 1B) $(26,27)$ to regulate embryonic development $(28)$; thus, caspase8 -mediated apoptosis and necroptosis compete with each other by cleaving different downstream substrates. In addition to being activated in the "programmed" cell death DISC, which is involved in apoptosis and necroptosis, caspase- 8 is also activated in inflammasome complexes and controls inflammasome activation (29) to induce microglial activation (30). Accordingly, caspase- 8 deficiency in humans causes defects in the activation of lymphocytes and natural killer cells, indicating the critical role of caspase- 8 in the immune activation of lymphocytes $(31,32)$. Moreover, the DISC components FADD and caspase-8 regulate NLRP3 inflammasome priming and activation (Figure 1C) $(29,33$,

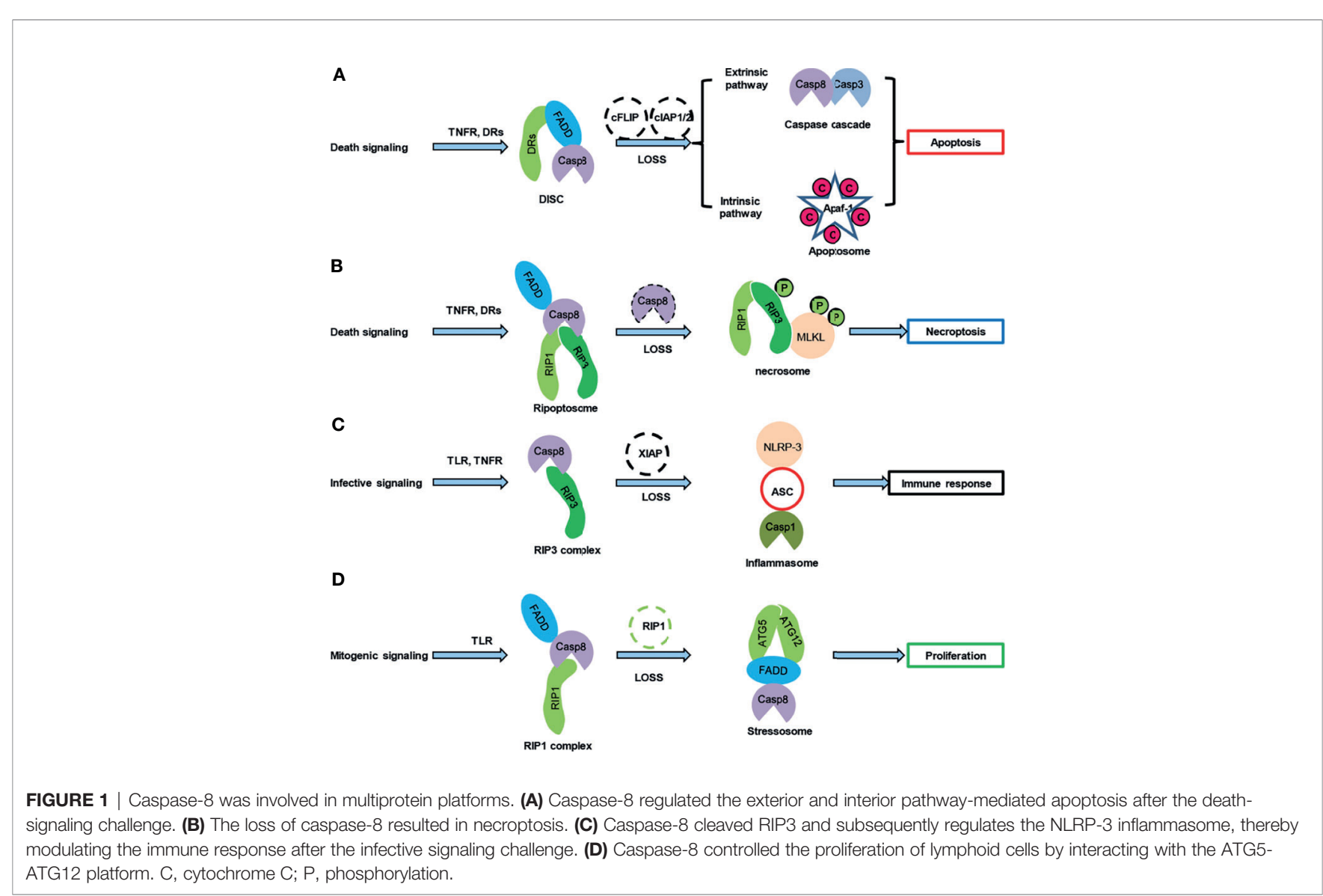


34), suggesting that DISC and inflammasome complexes might intercross with each other.

\section{CASPASE-8 ACTIVATION BY BORTEZOMIB AND LENALIDOMIDE IN MYELOMA CELLS}

Bortezomib (PS-341), a reversible proteasome inhibitor, was approved by the FDA for the treatment of multiple myeloma in 2003 (35). Similarly, lenalidomide and pomalidomide have been approved by the FDA, in 2005 and 2013, respectively, for the treatment of multiple myeloma (36). Since then, the bortezomib-lenalidomide combination has been used as the first-line treatment for multiple myeloma (37-39); however, there is a therapeutic paradox associated with lenalidomide and bortezomib treatment in myeloma (17). Bortezomib could potentiate the anti-myeloma effect of lenalidomide by stabilizing CRBN after short-term treatment in myeloma cells (13). Furthermore, although bortezomib blocks the degradation of IKZF1/3, ubiquitinated IKZF1/3 might not have transcriptional activity, and thus could mediate the anti-myeloma effect of lenalidomide (17).

Bortezomib activates caspase- 8 in myeloma cells, thereby inducing apoptosis of myeloma cells (4). Bortezomib induced oxidative stress in human hepatoma HepG2 cells and subsequently activated JNK, thereby activating caspase- 8 by increasing the FasL expression (40), which is dependent on the death receptor. Moreover, bortezomib could induce autophagy and then activate caspase- 8 in a death receptor-independent manner (41). Interestingly, the relationship between autophagy and caspase- 8 was first identified in T lymphocytes (42), and low activated caspase- 8 was required for $\mathrm{T}$-cell proliferation (Figure 1D) $(42,43)$.

Lenalidomide recruits the neo-substrate IKZF1/3 onto CRBN and promotes ubiquitination and subsequent degradation by the CRL4 ${ }^{\text {CRBN }}$ E3 ligase, thereby exhibiting an anti-myeloma effect (7-9). Although the anti-proliferative effect constitutes the major anti-myeloma effect of lenalidomide, a caspase- 8 fluorometric assay indicated that lenalidomide and pomalidomide could activate caspase-8 $(3,44,45)$. Nonetheless, active caspase-8mediated apoptosis of myeloma cells might be an edge effect of lenalidomide, because cleaved caspase- 8 was not detected after a lenalidomide challenge in myeloma cells $(5,44,45)$, which indicated that lenalidomide might promote the activities of caspase- 8 to low levels that are non-lethal for myeloma cells.

Caspase- 8 might participate in different multiprotein platforms to regulate apoptosis, necroptosis, pyroptosis, and proliferation (Figure 1) (46). The above mentioned cellular responses were regulated by the enzymatic and nonenzymatic activities of caspase-8, which depended on different cell types and drug-mediated induction. To dissect the enzymatic and nonenzymatic activities of caspase-8, conditional caspase- 8 knockout mice and derived cells were employed to investigate the possible functions of caspase- 8 in cellular responses $(47,48)$. Necroptosis in caspase-8-deficient mice was rescued by the deletion of Rip3 $(49,50)$ or Cyld $(51)$, suggesting that caspase8 exerted an antinecroptotic effect by cleaving RIP3 or CYLD. Mechanistically, the mixed-lineage kinase domain-like protein (MLKL) was phosphorylated by RIP3 and mediated TNF- $\alpha$ induced necroptosis (52-54). Embryos of enzymatically inactive caspase-8 (C362S) mice died after necroptosis and pyroptosis, which demonstrated that the enzymatic activity of caspase- 8 was crucial for suppressing necroptosis and pyroptosis and further underscored the suppressive effect of caspase-8-mediated apoptosis on necroptosis and pyroptosis $(46,55,56)$. The $M l k l$ deficiency rescued the necroptosis of caspase- 8 (C362S) mice but resulted inpyroptosis (46), which indicated that caspase-8mediated necroptosis might inhibit pyroptosis, thereby controlling normal embryonic development and adult tissue homeostasis (57).

The relatively high level of expression of caspase- 8 in lenalidomide-resistant RPMI-8226 cells suggested that the expression of caspase- 8 might affect lenalidomide sensitivity in myeloma cells (Figure 2A); however, this hypothesis has not been investigated yet. The relatively low expression or loss of

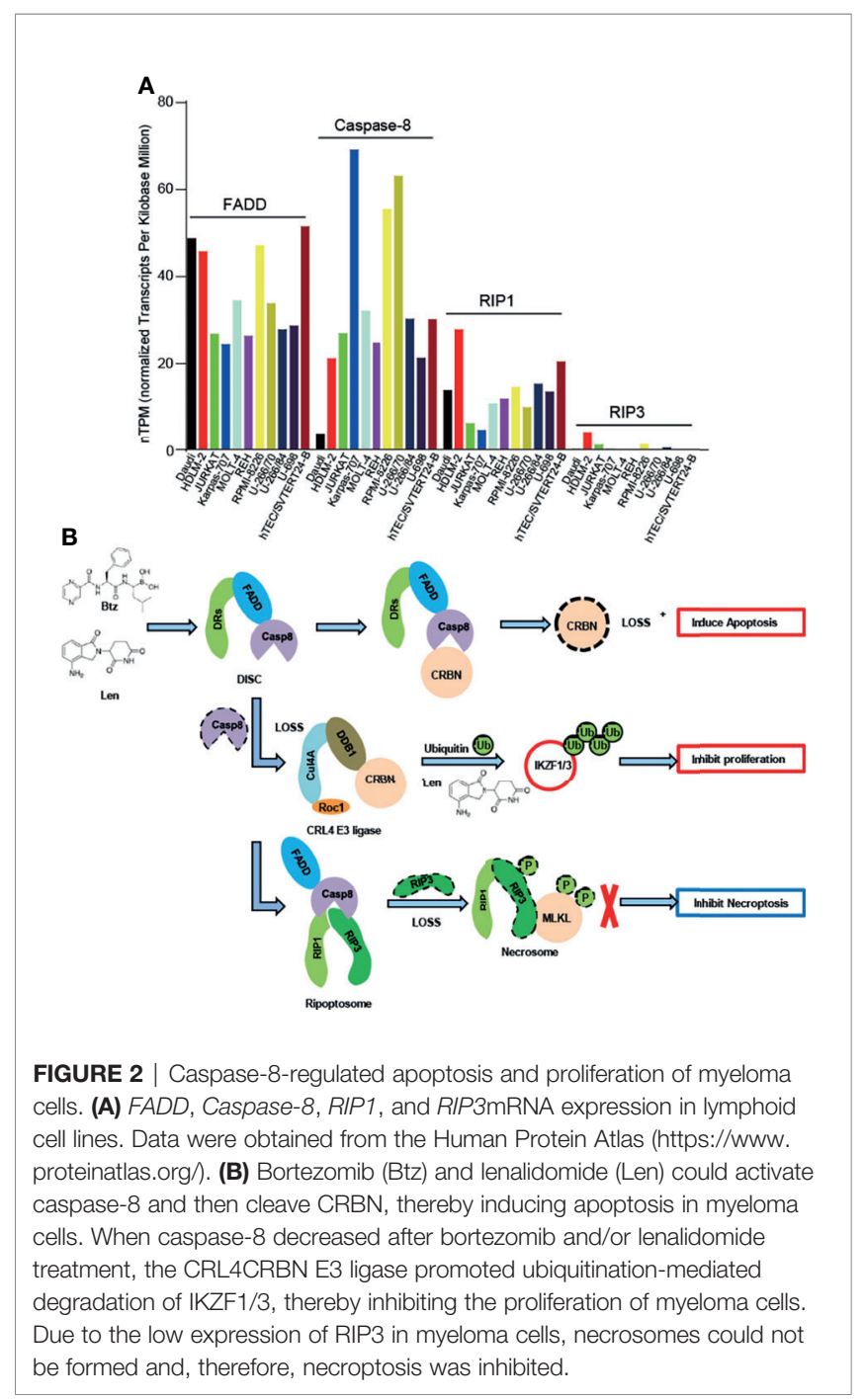


RIP3 expression in myeloma cells (Figure 2A) suggests that necroptosis and pyroptosis might be harder to induce than apoptosis, although this needs to be further investigated. Therefore, bortezomib and lenalidomide might not induce necroptosis and pyroptosis in myeloma cells (Figure 2A).

With continuous exposure to bortezomib and lenalidomide, bortezomib- and lenalidomide-resistant myeloma cells could be generated from their parental sensitive myeloma cells $(58,59)$. An examination of the relative expression levels of FADD, caspase-8, RIP1, and RIP3 in the lenalidomide- and bortezomib-resistant myeloma cells and their parental myeloma cells might help identify a possible programmed cell death pathway to overcome drug resistance.

\section{CASPASE-8-INDUCED CLEAVAGE OF CRBN IN MYELOMA CELLS}

CRBN is a lenalidomide-binding protein that mediates the antimyeloma effect of lenalidomide $(8,9,60)$. However, CRBN was not required for bortezomib-induced apoptosis in multiple myeloma (10). Nonetheless, bortezomib could potentiate the anti-myeloma effect of lenalidomide $(16,59)$, suggesting that bortezomib may regulate the CRBN-lenalidomide-IKZF1/3 signaling pathway. Accordingly, short-term bortezomib treatment inhibited the ubiquitination-mediated degradation of CRBN in myeloma cells, thereby potentiating the anti-myeloma effect of lenalidomide (13). Interestingly, long-term bortezomib treatment blocked the lenalidomide-induced degradation of neosubstrate IKZF1/3 (61) and induced CRBN cleavage (6), which might attenuate the anti-myeloma effect of lenalidomide (Figure 2B). Furthermore, as lenalidomide induced low activities of caspase-8, we demonstrated that lenalidomide could regulate the protein level of CRBN by inducing low expression of active caspase-8 (5). Therefore, these studies suggested that short-term bortezomib treatment potentiated the benefits of lenalidomide-based therapy of myeloma patients, whereas long-term bortezomib treatment attenuated the anti-myeloma effect of lenalidomide.

Caspase- 8 regulated NF- $\kappa \mathrm{B}$ activation in an enzymatic activity-dependent or an enzymatic activity-independent manner, which might be a cell type-or drug treatment-specific effect $(47,62,63)$. The enzymatic activity of caspase- 8 induced the release of DED-prodomain fragments, thereby activating NF$\mathrm{\kappa B}$ signaling in mouse embryonic fibroblasts following poly(I:C) stimulation (64). However, caspase- 8 bound to TRAF2 and FLASH, and thus mediated TNF- $\alpha$-induced NF- $\kappa \mathrm{B}$ activation in NIH3T3, HeLa, HEK293, and T cells, in an enzymatic activityindependent manner (65). Interestingly, the protein levels of CRBN and its neo-substrate IKZF1/3 were unaffected in TRAF2 knockout myeloma cells, although these TRAF2 knockout cells were resistant to both lenalidomide and pomalidomide (66), which suggested that the nonubiquitin functions of CRBN were crucial for cellular responses, such as proliferation. This hypothesis was underscored by the observations that CRBN inhibited NF- $\kappa \mathrm{B}$ activation by directly binding to TRAF6 (67,
68), thereby exhibiting nonubiquitin-mediated functions (69). Both caspase- 8 and CRBN contributed to NF- $\kappa \mathrm{B}$ activation, which further indicated an overlap between caspase- 8 and CRBN activities. However, the subsequent functions of CRBN cleavage by caspase -8 on NF- $\mathrm{\kappa B}$ activation and cellular responses have not been investigated.

\section{CASPASE-8-MEDIATED REGULATION OF LYMPHOID CELL PROLIFERATION}

FADD and caspase- 8 are essential for the cell-cycle progression of $\mathrm{T}$ cells, suggesting that caspase- 8 also regulated cell proliferation (Figure 1D) (43). In line with the above statement, low caspase- 8 activities were observed during normal $\mathrm{T}$ cell clonal expansion (42). Mechanistically, autophagy was activated in $\mathrm{T}$ cells after mitogenic ligand challenge and subsequent recruitment of caspase- 8 to FADD : Atg5-Atg12 multiprotein platforms, thereby promoting $\mathrm{T}$ cell proliferation (Figure 1D) (42). In caspase-8-deficient $\mathrm{T}$ cells, autophagy was hyperactivated (42), suggesting that physiologically low activated caspase- 8 suppressed the activation of autophagy. Conversely, autophagy could activate caspase-8 (41), indicating the presence of a feedback loop in caspase- 8 and autophagy activation in T cell expansion. Notably, the activation of caspase- 8 in proliferative $\mathrm{T}$ cells did not cause $\mathrm{T}$ cell death $(43,70)$, indicating that caspase- 8 was less activated during $\mathrm{T}$ cell proliferation. Thus, the sublethal activation of caspase- 8 regulated cell-cycle progression, whereas the elevation of active caspase- 8 expression following the blocking of protein degradation by bortezomib would be lethal for cells. Taken together, these data suggested that caspase- 8 was required for lymphocyte development and activation. Given that myeloma is a cancer of plasma cells, which are differentiated lymphocytes, the possible functions of caspase- 8 in the proliferation of myeloma cells need to be further investigated.

\section{FUTURE PERSPECTIVES}

Caspase- 8 plays a central role in "programmed" cell death, such as apoptosis, necroptosis, and pyroptosis, which is cell type- and drug treatment-specific $(46,71)$. Furthermore, caspase- 8 could enhance or attenuate the tumor malignancy, which is also a cell type- and drug treatment-specific function. Bortezomib and lenalidomide activate caspase- 8 and then cleave CRBN, thereby decreasing the sensitivity of the combination-treatment regimen of bortezomib and lenalidomide $(5,6)$. The inhibition or genetic depletion of caspase- 8 then stabilized CRBN, thereby promoting the antiproliferative effect of bortezomib and lenalidomide (6). The necrosome comprises RIP1, RIP3, and MLKL (72, 73). However, myeloma cells might not contain sufficient RIP3 (Figure 2A), suggesting that caspase- 8 inhibition and genetic depletion blocked not only apoptosis but also necroptosis and pyroptosis in myeloma cells (Figure 2B). Given that lenalidomide exerts an anti-myeloma effect by suppressing the 
proliferation of myeloma cells $(8,9)$, a physiologically low threshold concentration of active caspase- 8 cleaves CRBN and attenuates the anti-myeloma effect of bortezomib and lenalidomide, which is detrimental for myeloma patients. Clinically, it is possible to block the activity of caspase- 8 in myeloma patients, thereby enhancing the anti-myeloma effect of lenalidomide; however, no clinical study has evaluated the beneficial effect of caspase- 8 inhibition in myeloma patients. Therefore, the inhibition or genetic depletion of caspase- 8 might be beneficial for myeloma patients receiving lenalidomidebased therapy.

\section{REFERENCES}

1. Wang S, El-Deiry WS. TRAIL and Apoptosis Induction by TNF-Family Death Receptors. Oncogene (2003) 22(53):8628-33. doi: 10.1038/sj.onc. 1207232

2. Kantari C, Walczak H. Caspase- 8 and Bid: Caught in the Act Between Death Receptors and Mitochondria. Biochim Biophys Acta (BBA) - Mol Cell Res (2011) 1813(4):558-63. doi: 10.1016/j.bbamcr.2011.01.026

3. Mitsiades N, Mitsiades CS, Poulaki V, Chauhan D, Richardson PG, Hideshima $\mathrm{T}$, et al. Apoptotic Signaling Induced by Immunomodulatory Thalidomide Analogs in Human Multiple Myeloma Cells: Therapeutic Implications. Blood (2002) 99(12):4525-30. doi: 10.1182/blood.V99.12.4525

4. Chauhan D, Catley L, Li G, Podar K, Hideshima T, Velankar M, et al. A Novel Orally Active Proteasome Inhibitor Induces Apoptosis in Multiple Myeloma Cells With Mechanisms Distinct From Bortezomib. Cancer Cell (2005) 8 (5):407-19. doi: 10.1016/j.ccr.2005.10.013

5. Zhou L, Yu W, Jayabalan DS, Niesvizky R, Jaffrey SR, Huang X, et al. Caspase8 Inhibition Prevents the Cleavage and Degradation of E3 Ligase Substrate Receptor Cereblon and Potentiates its Biological Function. Front Cell Dev Biol (2020) 8:605989(1562):605989. doi: 10.3389/fcell.2020.605989

6. ZHOU L, Huang X, Niesvizky R, Pu Z, Xu G. Caspase-8 Regulates the AntiMyeloma Activity of Bortezomib and Lenalidomide. J Pharmacol Exp Ther (2021) 379:303-9. doi: 10.1124/jpet.121.000818

7. Ito T, Ando H, Suzuki T, Ogura T, Hotta K, Imamura Y, et al. Identification of a Primary Target of Thalidomide Teratogenicity. Sci (New York N.Y.) (2010) 327(5971):1345-50. doi: 10.1126/science.1177319

8. Krönke J, Udeshi ND, Narla A, Grauman P, Hurst SN, McConkey M, et al. Lenalidomide Causes Selective Degradation of IKZF1 and IKZF3 in Multiple Myeloma Cells. Sci (New York N.Y.) (2014) 343(6168):301-5. doi: 10.1126/ science. 1244851

9. Lu G, Middleton RE, Sun H, Naniong M, Ott CJ, Mitsiades CS, et al. The Myeloma Drug Lenalidomide Promotes the Cereblon-Dependent Destruction of Ikaros Proteins. Sci (New York N.Y.) (2014) 343(6168):305-9. doi: 10.1126/ science. 1244917

10. Zhu YX, Braggio E, Shi C-X, Bruins LA, Schmidt JE, Van Wier S, et al. Cereblon Expression is Required for the Antimyeloma Activity of Lenalidomide and Pomalidomide. Blood (2011) 118(18):4771-9. doi: 10.1182/blood-2011-05-356063

11. Lopez-Girona A, Mendy D, Ito T, Miller K, Gandhi AK, Kang J, et al. Cereblon is a Direct Protein Target for Immunomodulatory and Antiproliferative Activities of Lenalidomide and Pomalidomide. Leukemia (2012) 26 (11):2326-35. doi: 10.1038/leu.2012.119

12. Jian Y, Gao W, Geng C, Zhou H, Leng Y, Li Y, et al. Arsenic Trioxide Potentiates Sensitivity of Multiple Myeloma Cells to Lenalidomide by Upregulating Cereblon Expression Levels. Oncol Lett (2017) 14(3):3243-8. doi: 10.3892/ol.2017.6502

13. Liu J, Song T, Zhou W, Xing L, Wang S, Ho M, et al. A Genome-Scale CRISPR-Cas9 Screening in Myeloma Cells Identifies Regulators of Immunomodulatory Drug Sensitivity. Leukemia (2019) 33(1):171-80. doi: 10.1038/s41375-018-0205-y

14. Zheng J, Sha Y, Roof L, Foreman O, Lazarchick J, Venkta JK, et al. Pan-PIM Kinase Inhibitors Enhance Lenalidomide's Anti-Myeloma Activity via

\section{AUTHOR CONTRIBUTIONS}

The author confirms being the sole contributor of this work and has approved it for publication.

\section{FUNDING}

This work was supported by the National Natural Science Foundation of China (32170975).

Cereblon IKZF1/3 Cascade. Cancer Lett (2019) 440-441:1-10. doi: 10.1016 j.canlet.2018.10.003

15. Zou Y, Lin M, Sheng Z, Niu S. Bortezomib and Lenalidomide as Front-Line Therapy for Multiple Myeloma. Leukemia Lymphoma (2014) 55(9):2024-31. doi: 10.3109/10428194.2013.847935

16. Attal M, Lauwers-Cances V, Hulin C, Leleu X, Caillot D, Escoffre M, et al. Lenalidomide, Bortezomib, and Dexamethasone With Transplantation for Myeloma. New Engl J Med (2017) 376(14):1311-20. doi: 10.1056/ NEJMoa1611750

17. Wang B, Duan J, Zhou L. The Paradoxical Pharmacological Mechanisms of Lenalidomide and Bortezomib in the Treatment of Multiple Myeloma. AntiCancer Drugs (2021) 32(3):227-32. doi: 10.1097/CAD.0000000000001041

18. Chauhan D, Li G, Hideshima T, Podar K, Mitsiades C, Mitsiades N, et al. JNKDependent Release of Mitochondrial Protein, Smac, During Apoptosis in Multiple Myeloma (MM) Cells. J Biol Chem (2003) 278(20):17593-6. doi: 10.1074/jbc.C300076200

19. Field-Smith A, Morgan GJ, Davies FE. Bortezomib (Velcadetrade Mark) in the Treatment of Multiple Myeloma. Ther Clin Risk Manage (2006) 2(3):271-9. doi: $10.2147 /$ tcrm.2006.2.3.271

20. Hideshima T, Ikeda H, Chauhan D, Okawa Y, Raje N, Podar K, et al. Bortezomib Induces Canonical Nuclear Factor- $\kappa b$ Activation in Multiple Myeloma Cells. Blood (2009) 114(5):1046-52. doi: 10.1182/blood-2009-01199604

21. Verhelle D, Corral LG, Wong K, Mueller JH, Moutouh-de Parseval L, JensenPergakes K, et al. Lenalidomide and CC-4047 Inhibit the Proliferation of Malignant B Cells While Expanding Normal CD34+ Progenitor Cells. Cancer Res (2007) 67(2):746-55. doi: 10.1158/0008-5472.can-06-2317

22. Kotla V, Goel S, Nischal S, Heuck C, Vivek K, Das B, et al. Mechanism of Action of Lenalidomide in Hematological Malignancies. J Hematol Oncol (2009) 2(1):36. doi: 10.1186/1756-8722-2-36

23. Fulda S, Debatin KM. Extrinsic Versus Intrinsic Apoptosis Pathways in Anticancer Chemotherapy. Oncogene (2006) 25(34):4798-811. doi: 10.1038/ sj.onc. 1209608

24. Wang L, Du F, Wang X. TNF- $\alpha$ Induces Two Distinct Caspase- 8 Activation Pathways. Cell (2008) 133(4):693-703. doi: 10.1016/j.cell.2008.03.036

25. Baumgartner HK, Gerasimenko JV, Thorne C, Ashurst LH, Barrow SL, Chvanov MA, et al. Caspase-8-Mediated Apoptosis Induced by Oxidative Stress is Independent of the Intrinsic Pathway and Dependent on Cathepsins. Am J Physiology-Gastrointestinal Liver Physiol (2007) 293(1):G296-307. doi: 10.1152/ajpgi.00103.2007

26. Lin Y, Devin A, Rodriguez Y, Liu Z-G. Cleavage of the Death Domain Kinase RIP by Caspase-8 Prompts TNF-Induced Apoptosis. Genes Dev (1999) 13 (19):2514-26. doi: 10.1101/gad.13.19.2514

27. Feng S, Yang Y, Mei Y, Ma L, Zhu D-E, Hoti N, et al. Cleavage of RIP3 Inactivates its Caspase-Independent Apoptosis Pathway by Removal of Kinase Domain. Cell Signalling (2007) 19(10):2056-67. doi: 10.1016/j.cellsig. 2007.05.016

28. Newton K, Wickliffe KE, Dugger DL, Maltzman A, Roose-Girma M, Dohse M, et al. Cleavage of RIPK1 by Caspase- 8 is Crucial for Limiting Apoptosis and Necroptosis. Nature (2019) 574(7778):428-31. doi: 10.1038/s41586-019-1548-x

29. Gurung P, Anand PK, Malireddi RKS, Vande Walle L, Van Opdenbosch N, Dillon CP, et al. FADD and Caspase- 8 Mediate Priming and Activation of the 
Canonical and Noncanonical Nlrp3 Inflammasomes. J Immunol (2014) 192 (4):1835-46. doi: 10.4049/jimmunol.1302839

30. Burguillos MA, Deierborg T, Kavanagh E, Persson A, Hajji N, GarciaQuintanilla A, et al. Caspase Signalling Controls Microglia Activation and Neurotoxicity. Nature (2011) 472(7343):319-24. doi: 10.1038/nature09788

31. Chun HJ, Zheng L, Ahmad M, Wang J, Speirs CK, Siegel RM, et al. Pleiotropic Defects in Lymphocyte Activation Caused by Caspase-8 Mutations Lead to Human Immunodeficiency. Nature (2002) 419(6905):395-9. doi: 10.1038/ nature 01063

32. Lehle AS, Farin HF, Marquardt B, Michels BE, Magg T, Li Y, et al. Intestinal Inflammation and Dysregulated Immunity in Patients With Inherited Caspase-8 Deficiency. Gastroenterology (2019) 156(1):275-8. doi: 10.1053/ j.gastro.2018.09.041

33. Swanson KV, Deng M, Ting JPY. The NLRP3 Inflammasome: Molecular Activation and Regulation to Therapeutics. Nat Rev Immunol (2019) 19 (8):477-89. doi: 10.1038/s41577-019-0165-0

34. Han J-H, Park J, Kang T-B, Lee K-H. Regulation of Caspase-8 Activity at the Crossroads of Pro-Inflammation and Anti-Inflammation. Int J Mol Sci (2021) 22(7):3318. doi: 10.3390/ijms22073318

35. Kane RC, Bross PF, Farrell AT, Pazdur R. Velcade ${ }^{\circledR}$ : U.S. FDA Approval for the Treatment of Multiple Myeloma Progressing on Prior Therapy. Oncologist (2003) 8(6):508-13. doi: 10.1634/theoncologist.8-6-508

36. Holstein SA, McCarthy PL. Immunomodulatory Drugs in Multiple Myeloma: Mechanisms of Action and Clinical Experience. Drugs (2017) 77(5):505-20. doi: 10.1007/s40265-017-0689-1

37. Richardson PG, Weller E, Lonial S, Jakubowiak AJ, Jagannath S, Raje NS, et al. Lenalidomide, Bortezomib, and Dexamethasone Combination Therapy in Patients With Newly Diagnosed Multiple Myeloma. Blood (2010) 116(5):67986. doi: 10.1182/blood-2010-02-268862

38. Durie B, Hoering A, Rajkumar SV, Abidi MH, Epstein J, Kahanic SP, et al. Bortezomib, Lenalidomide and Dexamethasone Vs. Lenalidomide and Dexamethasone in Patients (Pts) With Previously Untreated Multiple Myeloma Without an Intent for Immediate Autologous Stem Cell Transplant (ASCT): Results of the Randomized Phase III Trial SWOG S0777. Blood (2015) 126(23):25-5. doi: 10.1182/blood.V126.23.25.25

39. Durie BGM, Hoering A, Abidi MH, Rajkumar SV, Epstein J, Kahanic SP, et al. Bortezomib With Lenalidomide and Dexamethasone Versus Lenalidomide and Dexamethasone Alone in Patients With Newly Diagnosed Myeloma Without Intent for Immediate Autologous Stem-Cell Transplant (SWOG S0777): A Randomised, Open-Label, Phase 3 Trial. Lancet (London England) (2017) 389(10068):519-27. doi: 10.1016/s0140-6736(16)31594-x

40. Lauricella M, Emanuele S, D'Anneo A, Calvaruso G, Vassallo B, Carlisi D, et al. JNK and AP-1 Mediate Apoptosis Induced by Bortezomib in HepG2 Cells via FasL/caspase-8 and Mitochondria-Dependent Pathways. Apoptosis (2006) 11(4):607-25. doi: 10.1007/s10495-006-4689-y

41. Laussmann MA, Passante E, Düssmann H, Rauen JA, Würstle ML, Delgado ME, et al. Proteasome Inhibition can Induce an Autophagy-Dependent Apical Activation of Caspase-8. Cell Death Differ (2011) 18(10):1584-97. doi: $10.1038 /$ cdd.2011.27

42. Bell BD, Leverrier S, Weist BM, Newton RH, Arechiga AF, Luhrs KA, et al. FADD and Caspase-8 Control the Outcome of Autophagic Signaling in Proliferating T Cells. Proc Natl Acad Sci (2008) 105(43):16677-82. doi: 10.1073/pnas.0808597105

43. Arechiga AF, Bell BD, Leverrier S, Weist BM, Porter M, Wu Z, et al. A Fas-Associated Death Domain Protein/Caspase-8-Signaling Axis Promotes s-Phase Entry and Maintains S6 Kinase Activity in T Cells Responding to IL-2. J Immunol (2007) 179(8):5291-300. doi: 10.4049/jimmunol.179.8.5291

44. Chauhan D, Singh AV, Ciccarelli B, Richardson PG, Palladino MA, Anderson KC. Combination of Novel Proteasome Inhibitor NPI-0052 and Lenalidomide Trigger In Vitro and In Vivo Synergistic Cytotoxicity in Multiple Myeloma. Blood (2010) 115(4):834-45. doi: 10.1182/blood-2009-03-213009

45. Das DS, Ray A, Song Y, Richardson P, Trikha M, Chauhan D, et al. Synergistic Anti-Myeloma Activity of the Proteasome Inhibitor Marizomib and the IMiD Immunomodulatory Drug Pomalidomide. Br J haematology (2015) 171 (5):798-812. doi: 10.1111/bjh.13780

46. Fritsch M, Günther SD, Schwarzer R, Albert M-C, Schorn F, Werthenbach JP, et al. Caspase- 8 is the Molecular Switch for Apoptosis, Necroptosis and Pyroptosis. Nature (2019) 575(7784):683-7. doi: 10.1038/s41586-019-1770-6
47. Henry CM, Martin SJ. Caspase-8 Acts in a non-Enzymatic Role as a Scaffold for Assembly of a Pro-Inflammatory "FADDosome" Complex Upon TRAIL Stimulation. Mol Cell (2017) 65(4):715-729.e715. doi: 10.1016/j.molcel. 2017.01.022

48. DeLaney AA, Berry CT, Christian DA, Hart A, Bjanes E, Wynosky-Dolfi MA, et al. Caspase-8 Promotes C-Rel-dependent Inflammatory Cytokine Expression and Resistance Against Toxoplasma Gondii. Proc Natl Acad Sci (2019) 116(24):11926-35. doi: 10.1073/pnas.1820529116

49. Kaiser WJ, Upton JW, Long AB, Livingston-Rosanoff D, Daley-Bauer LP, Hakem R, et al. RIP3 Mediates the Embryonic Lethality of Caspase-8Deficient Mice. Nature (2011) 471(7338):368-72. doi: 10.1038/nature09857

50. Oberst A, Dillon CP, Weinlich R, McCormick LL, Fitzgerald P, Pop C, et al. Catalytic Activity of the Caspase-8-FLIPL Complex Inhibits RIPK3-Dependent Necrosis. Nature (2011) 471(7338):363-7. doi: 10.1038/ nature 09852

51. O'Donnell MA, Perez-Jimenez E, Oberst A, Ng A, Massoumi R, Xavier R, et al. Caspase 8 Inhibits Programmed Necrosis by Processing CYLD. Nat Cell Biol (2011) 13(12):1437-42. doi: 10.1038/ncb2362

52. Sun L, Wang H, Wang Z, He S, Chen S, Liao D, et al. Mixed Lineage Kinase Domain-Like Protein Mediates Necrosis Signaling Downstream of RIP3 Kinase. Cell (2012) 148(1):213-27. doi: 10.1016/j.cell.2011.11.031

53. Cai Z, Jitkaew S, Zhao J, Chiang H-C, Choksi S, Liu J, et al. Plasma Membrane Translocation of Trimerized MLKL Protein is Required for TNF-Induced Necroptosis. Nat Cell Biol (2014) 16(1):55-65. doi: 10.1038/ncb2883

54. Chen X, Li W, Ren J, Huang D, He W-T, Song Y, et al. Translocation of Mixed Lineage Kinase Domain-Like Protein to Plasma Membrane Leads to Necrotic Cell Death. Cell Res (2014) 24(1):105-21. doi: 10.1038/cr.2013.171

55. Samir P, Malireddi RKS, Kanneganti T-D. The PANoptosome: A Deadly Protein Complex Driving Pyroptosis, Apoptosis, and Necroptosis (PANoptosis). Front Cell Infection Microbiol (2020) 10:238(238). doi: $10.3389 /$ fcimb. 2020.00238

56. Wang Y, Kanneganti T-D. From Pyroptosis, Apoptosis and Necroptosis to PANoptosis: A Mechanistic Compendium of Programmed Cell Death Pathways. Comput Struct Biotechnol J (2021) 19:4641-57. doi: 10.1016/ j.csbj.2021.07.038

57. Frank D, Vince JE. Pyroptosis Versus Necroptosis: Similarities, Differences, and Crosstalk. Cell Death Differ (2019) 26(1):99-114. doi: 10.1038/s41418018-0212-6

58. Ri M, Iida S, Nakashima T, Miyazaki H, Mori F, Ito A, et al. BortezomibResistant Myeloma Cell Lines: A Role for Mutated PSMB5 in Preventing the Accumulation of Unfolded Proteins and Fatal ER Stress. Leukemia (2010) 24 (8):1506-12. doi: 10.1038/leu.2010.137

59. Zhu YX, Shi C-X, Bruins LA, Wang X, Riggs DL, Porter B, et al. Identification of Lenalidomide Resistance Pathways in Myeloma and Targeted Resensitization Using Cereblon Replacement, Inhibition of STAT3 or Targeting of IRF4. Blood Cancer J (2019) 9(2):19. doi: 10.1038/s41408-019-0173-0

60. Heider M, Eichner R, Stroh J, Morath V, Kuisl A, Zecha J, et al. The IMiD Target CRBN Determines HSP90 Activity Toward Transmembrane Proteins Essential in Multiple Myeloma. Mol Cell (2021) 81(6):1170-1186.e1110. doi: 10.1016/.j.molcel.2020.12.046

61. Shi C-X, Kortüm KM, Zhu YX, Jedlowski P, Bruins L, Braggio E, et al. Proteasome Inhibitors Block Ikaros Degradation by Lenalidomide in Multiple Myeloma. Haematologica (2015) 100(8):e315-7. doi: 10.3324/haematol. 2015.124297

62. Su H, Bidère N, Zheng L, Cubre A, Sakai K, Dale J, et al. Requirement for Caspase-8 in NF-kb Activation by Antigen Receptor. Sci (New York N.Y.) (2005) 307(5714):1465-8. doi: 10.1126/science.1104765

63. Lamkanfi M, Festjens N, Declercq W, Berghe TV, Vandenabeele P. Caspases in Cell Survival, Proliferation and Differentiation. Cell Death Differ (2007) 14 (1):44-55. doi: 10.1038/sj.cdd.4402047

64. Takahashi K, Kawai T, Kumar H, Sato S, Yonehara S, Akira S. Cutting Edge: Roles of Caspase-8 and Caspase-10 in Innate Immune Responses to DoubleStranded RNA. J Immunol (2006) 176(8):4520-4. doi: 10.4049/jimmunol. 176.8 .4520

65. Jun J-I, Chung C-W, Lee H-J, Pyo J-O, Lee KN, Kim N-S, et al. Role of FLASH in Caspase-8-Mediated Activation of NF-Kb: Dominant-Negative Function of FLASH Mutant in NF-kb Signaling Pathway. Oncogene (2005) 24(4):688-96. doi: $10.1038 /$ sj.onc. 1208186 
66. Liu J, Zhou W, Xing L, Lin L, Wen K, Tai Y-T, et al. Genome-Wide CRISPRCas9 Screening Reveals a Role for TRAF2 in Resistance to IMiDs in Multiple Myeloma. Blood (2018) 132:1917-7. doi: 10.1182/blood-2018-99-111962

67. Min Y, Wi SM, Kang J-A, Yang T, Park C-S, Park S-G, et al. Cereblon Negatively Regulates TLR4 Signaling Through the Attenuation of Ubiquitination of TRAF6. Cell Death Dis (2016) 7(7):e2313-3. doi: 10.1038/cddis.2016.226

68. Kim M-J, Min Y, Shim J-H, Chun E, Lee K-Y. CRBN is a Negative Regulator of Bactericidal Activity and Autophagy Activation Through Inhibiting the Ubiquitination of ECSIT and BECN1. Front Immunol (2019) 10:2203(2203). doi: 10.3389/fimmu.2019.02203

69. Zhou L, Xu G. The Ubiquitination-Dependent and -Independent Functions of Cereblon in Cancer and Neurological Diseases. J Mol Biol (2022) 434 (5):167457. doi: 10.1016/j.jmb.2022.167457

70. Ch'en IL, Beisner DR, Degterev A, Lynch C, Yuan J, Hoffmann A, et al. Antigen-Mediated T Cell Expansion Regulated by Parallel Pathways of Death. Proc Natl Acad Sci (2008) 105(45):17463-8. doi: 10.1073/pnas.0808043105

71. Bertheloot D, Latz E, Franklin BS. Necroptosis, Pyroptosis and Apoptosis: An Intricate Game of Cell Death. Cell Mol Immunol (2021) 18(5):1106-21. doi: 10.1038/s41423-020-00630-3

72. Wu XN, Yang ZH, Wang XK, Zhang Y, Wan H, Song Y, et al. Distinct Roles of RIP1-RIP3 Hetero- and RIP3-RIP3 Homo-Interaction in Mediating Necroptosis. Cell Death Differ (2014) 21(11):1709-20. doi: 10.1038/cdd.2014.77
73. Wu Y, Zheng Z, Cao X, Yang Q, Norton V, Adini A, et al. RIP1/RIP3/MLKL Mediates Myocardial Function Through Necroptosis in Experimental Autoimmune Myocarditis. Front Cardiovasc Med (2021) 8:696362(928). doi: $10.3389 /$ fcvm.2021.696362

Conflict of Interest: The author declares that the research was conducted in the absence of any commercial or financial relationships that could be construed as a potential conflict of interest.

Publisher's Note: All claims expressed in this article are solely those of the authors and do not necessarily represent those of their affiliated organizations, or those of the publisher, the editors and the reviewers. Any product that may be evaluated in this article, or claim that may be made by its manufacturer, is not guaranteed or endorsed by the publisher.

Copyright $\odot 2022$ Zhou. This is an open-access article distributed under the terms of the Creative Commons Attribution License (CC BY). The use, distribution or reproduction in other forums is permitted, provided the original author(s) and the copyright owner(s) are credited and that the original publication in this journal is cited, in accordance with accepted academic practice. No use, distribution or reproduction is permitted which does not comply with these terms. 